\title{
Near-Sea Surface Temperature Stratification from SVP Drifters
}

\author{
G. Reverdin, S. Morisset, H. Bellenger, J. Boutin, And N. Martin \\ LOCEAN/IPSL (CNRS/UPMC/IRD/MNHN), Paris, France \\ P. BLOUCH AND J. ROLLAND \\ CMM, CNRM, Brest, France \\ F. GAILLARD \\ Laboratoire de Physique des Océans, IFREMER, Brest, France \\ P. BOURUET-AUBERTOT \\ LOCEAN/IPSL (CNRS/UPMC/IRD/MNHN), Paris, France \\ B. WARD \\ School of Physics, National University of Ireland, Galway, Ireland
}

(Manuscript received 10 August 2012, in final form 21 February 2013)

\begin{abstract}
This study describes how the hull temperature (Ttop) measurements from multisensor surface velocity program (SVP) drifters can be combined with other measurements to provide quantitative information on nearsurface vertical temperature stratification during large daily cycles. First, Ttop is compared to the temperature measured at $17-\mathrm{cm}$ depth from a float tethered to the SVP drifter. These 2007-12 SVP drifters present a larger daily cycle by $1 \%-3 \%$ for $1^{\circ}-2^{\circ} \mathrm{C}$ daily cycle amplitudes, with a maximum difference close to the local noon. The difference could result from flow around the SVP drifter in the presence of temperature stratification in the top $20 \mathrm{~cm}$ of the water column but also from a small influence of internal drifter temperature on Ttop. The largest differences were found for small drifters (Technocean) for very large daily cycles, as expected from their shallower measurements. The vertical stratification is estimated by comparing these hull data with the deeper $T$ or conductivity $C$ measurements from Sea-Bird sensors 25 (Pacific Gyre) to $45 \mathrm{~cm}$ (MetOcean) below the top temperature sensor. The largest stratification is usually found near local noon and early afternoon. For a daily cycle amplitude of $1^{\circ} \mathrm{C}$, these differences with the upper level are in the range of $3 \%-5 \%$ of the daily cycle for the Pacific Gyre drifters and 6\%-10\% for MetOcean drifters with the largest values occurring when the midday sun elevation is lowest. The relative differences increase for larger daily cycles, and the vertical profiles become less linear. These estimated stratifications are well above the uncertainty on Ttop.
\end{abstract}

\section{Introduction}

Diurnal warm surface layers impact the estimates of air-sea flux exchanges (Fairall et al. 1996; Ward 2006). They need to be taken into account to estimate average

Corresponding author address: G. Reverdin, Expérimentation et Analyse Numérique, Laboratoire d'Océanographie Dynamique et de Climatologie, Université Pierre et Marie Curie, Institut Pierre Simon Laplace, Case 100, 4 Place Jussieu, 75252 Paris CEDEX 05, France.

E-mail: gilles.reverdin@locean-ipsl.upmc.fr sea surface temperature (SST) and its variability, from intraseasonal to interannual and even on climate variability scales (Shinoda 2005; Bernie et al. 2005; Bellenger et Duvel 2009). The SST daily cycles are very variable in the ocean, to a large extent in relation to insolation and wind intensity (Gentemann et al. 2009). They are most commonly less that $0.5^{\circ} \mathrm{C}$ amplitude even in the tropics; however, in $4.3 \%$ of the tropical oceans $\left(25^{\circ} \mathrm{N}-25^{\circ} \mathrm{S}\right)$, a model approach indicates that the daily temperature $T$ maximum exceeds the early morning minimum by more than $1.0^{\circ} \mathrm{C}$ (Bellenger and Duvel 2009). This 


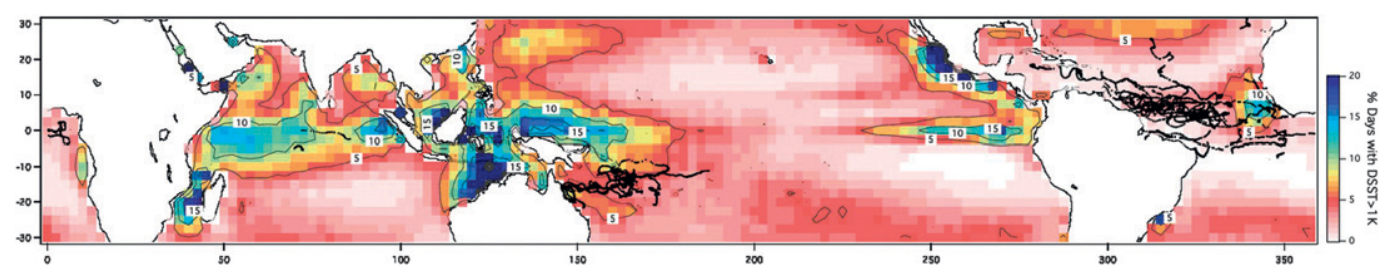

FIG. 1. Percent of days with daily cycles $>1{ }^{\circ} \mathrm{C}$ in the tropics, based on model simulations by Bellenger and Duvel (2009). Positions of the MetOcean and Pacific Gyre SVP-BS drifter data used in this study are overlaid on the figure.

model reproduces the spatial distributions found with satellite SSTs (Stuart-Menteth et al. 2003; Merchant et al. 2008; Gentemann et al. 2008; Marullo et al. 2010).

Strong SST diurnal variations $\left(>1^{\circ} \mathrm{C}\right)$ are relatively more frequent in the Indo-Pacific part of the intertropical convergence zone (ITCZ); the eastern equatorial Pacific Ocean, along the coast of Mexico; and in the Mozambique channel, where they can be observed more than $15 \%$ of the time (Fig. 1). These diurnal warm layers directly impact the surface heat fluxes with a typical increase of net heat flux of $50 \mathrm{~W} \mathrm{~m}^{-2}$ around noon for an increase of SST of $2^{\circ} \mathrm{C}$ (Fairall et al. 1996). They thus modify the simulated climate and its variability (Brunke et al. 2008), and should be taken into account to improve weather predictions in the tropics (Woolnough et al. 2007). In particular, diurnal SST variations can trigger shallow convection during the afternoon over tropical oceans (Parsons et al. 2000; Kawai and Wada 2007; Bellenger et al. 2010); this participates in the atmospheric preconditioning prior to the onset of the active phase of the Madden-Julian oscillation (Johnson et al. 1999).

Near-surface drifter measurements are a core dataset used to verify and validate satellite used to map SST (in particular, infrared-derived temperatures; Emery et al. 2001; O'Carroll et al. 2008). They also provide valuable information on daily cycles of near-surface temperature (Kennedy et al. 2007; Kawai and Kawamura 2002; Bellenger and Duvel 2009; Filipiak et al. 2012; Le Borgne et al. 2012). Recently, the accuracy and the representativeness of surface velocity program (SVP) drifter temperatures to estimate SST have been challenged (Castro et al. 2012; Reverdin et al. 2010). One issue only briefly discussed in those papers relates to the use of these measurements for investigating near-surface stratification, in particular for midday surface warming (cf. Fig. 3 in Reverdin et al. 2010). How close is the water temperature to the temperature measured? For other buoys, platform effects (Yokoyama et al. 1995; Kawai and Kawamura 2000; Kawai et al. 2009) result in perturbing the temperature profile around the buoy, either because of modifications of the penetrating solar radiation or because of the water mixing induced by the buoy, resulting in transferring heat downward. The downward heat transfer results in increasing the measured temperature, as if its depth was reduced. We will refer to this depth as the equivalent depth of the temperature measurement.

To investigate the relevance of the drifter hull temperature measurements for near-surface stratification studies, we will first compare them with observations at a fixed level with respect to the sea surface by attaching a small instrumented float to the SVP drifter (section 3). For validation purposes, we will consider instances of large daytime warming. We will thus characterize platform effects of this drifter, in particular as a reduced equivalent depth. We will then investigate whether the combination of the different data on multisensor drifters can be used to estimate temperature gradients in this layer (section 4). For that, we will check how it varies throughout the day as a function of the amplitude of the temperature daily cycle near the surface. For comparison purposes, we will present Skin Depth Experimental Profiler (SkinDeEP) near-surface temperature gradient data from three separate deployments (equatorial Pacific, Gulf of California, and Mediterranean) (Ward et al. 2004a).

Such validated data on vertical stratification could provide a basis for further validation of existing models of the near-surface temperature daily cycle, as in the empirical profiles of ocean surface heating (POSH) model (Gentemann et al. 2009).

\section{Data and methods}

\section{a. The drifters}

SVP drifters have been designed in fairly standard ways since the late 1980s, with the temperature sensor set fairly close to the bottom of the surface spherical float. The prime characteristics of the main drifter types used are summarized in Table 1. This spherical float comes in different sizes. Most drifters prior to 2003 have a large spherical float (41-cm diameter). After 2003, some have a large spherical float [including the ones instrumented with Sea-Bird Electronics conductivity/ temperature (SBE $C / T$ ) sensors used in the present paper], whereas most have a smaller sphere (including most 
TABLE 1. Summary of characteristics of the different drifters. Depths are measured relative to the drifter equator (see Fig. 2). Averaging times relate to the times during which the measurement was taken.

\begin{tabular}{lcccccc}
\hline \hline \multicolumn{1}{c}{ Drifter type } & $\begin{array}{c}\text { Hull } \\
\text { diameter }(\mathrm{cm})\end{array}$ & $\begin{array}{c}\text { Depth of } \\
\text { Ttop }(\mathrm{cm})\end{array}$ & $\begin{array}{c}\text { Averaging time } \\
\text { of Ttop }(\mathrm{min})\end{array}$ & $\begin{array}{c}\text { Depth Tsal } \\
(\mathrm{cm})\end{array}$ & $\begin{array}{c}\text { Depth } C \text { cell } \\
(\mathrm{cm})\end{array}$ & $\begin{array}{c}\text { Averaging time } \\
\text { of Tsal/C }\end{array}$ \\
\hline Pacific Gyre SVP-BS & 41 & 17.5 & 30 & 43 & $27-49$ & $5 \mathrm{~min}$ \\
MetOcean SVP-BS & 41 & 17.5 & 15 & 62 & $52-72$ & $15 \mathrm{~min}$ \\
Technocean SVP & 28 & $13-15$ & 15 & 17 & 15.5 & $8 \mathrm{~s}$ \\
Surplas & 10 by 13 & & & & \\
\hline
\end{tabular}

of the 2009 and 2010 Technocean SVP drifters mentioned in this paper). The surface float is attached by a tether to a subsurface drogue centered at $15-\mathrm{m}$ depth. The ensemble is designed so that without wind, the equator of the surface sphere is close to the surface (the manual mentions $2.5 \mathrm{~cm}$ above the water line). However, when the drogue is attached and there is some wind, the surface float plunges into the waves and its average depth relative to the sea surface will be larger. When the drogue is lost, more of the sphere will be out of water.

The temperature is measured by a thermistor glued inside a stainless steel cap with epoxy resin Stycast and installed either just under the hull in a bulging housing (MetOcean and Technocean drifters) or in contact with a thermally conductive flat housing (for the Pacific Gyre drifters mentioned in this study). Additional details are reported in Castro et al. (2012). The housing is placed in the lower hemisphere of the hull (a depth of $2-3 \mathrm{~cm}$ above the lowest point of the sphere). This setting places the housing roughly $17-18 \mathrm{~cm}$ under the water line for the larger spheres [for this study, these are MetOcean and Pacific Gyre SVP barometers with salinity (SVP-BS) drifters] and $13-15 \mathrm{~cm}$ for the smaller spheres (here, Technocean; Fig. 2). When the drogue is present, the housing depth with respect to the sea surface will be deeper a notable part of the time, as discussed above; however, when the drogue is lost, it might be much shallower.

The temperature data are averaged over $15 \mathrm{~min}$ for Technocean and MetOcean drifters, and over $30 \mathrm{~min}$ for Pacific Gyre drifters. There is a thermal lag originating mostly from the thermal conductivity and response time of the housing. It is typically on the order of $15 \mathrm{~min}$ for the drifters investigated. For MetOcean and Technocean drifters, the time reported for the measurement has been shifted to take into account both the thermal lag and this averaging period. The resolution of the reported data has changed considerably in time. For the drifters in this study, it varies between near $0.01^{\circ}$ (recent models) and $0.10^{\circ} \mathrm{C}$. We will refer to these measurements as Ttop. The accuracy of the temperature measurements is discussed in Castro et al. (2012) and Reverdin et al. (2010). This encompasses the sensor absolute accuracy, which does not always fit the specification of $0.1^{\circ} \mathrm{C}$ accuracy even at deployment, as well as the drifts in time.

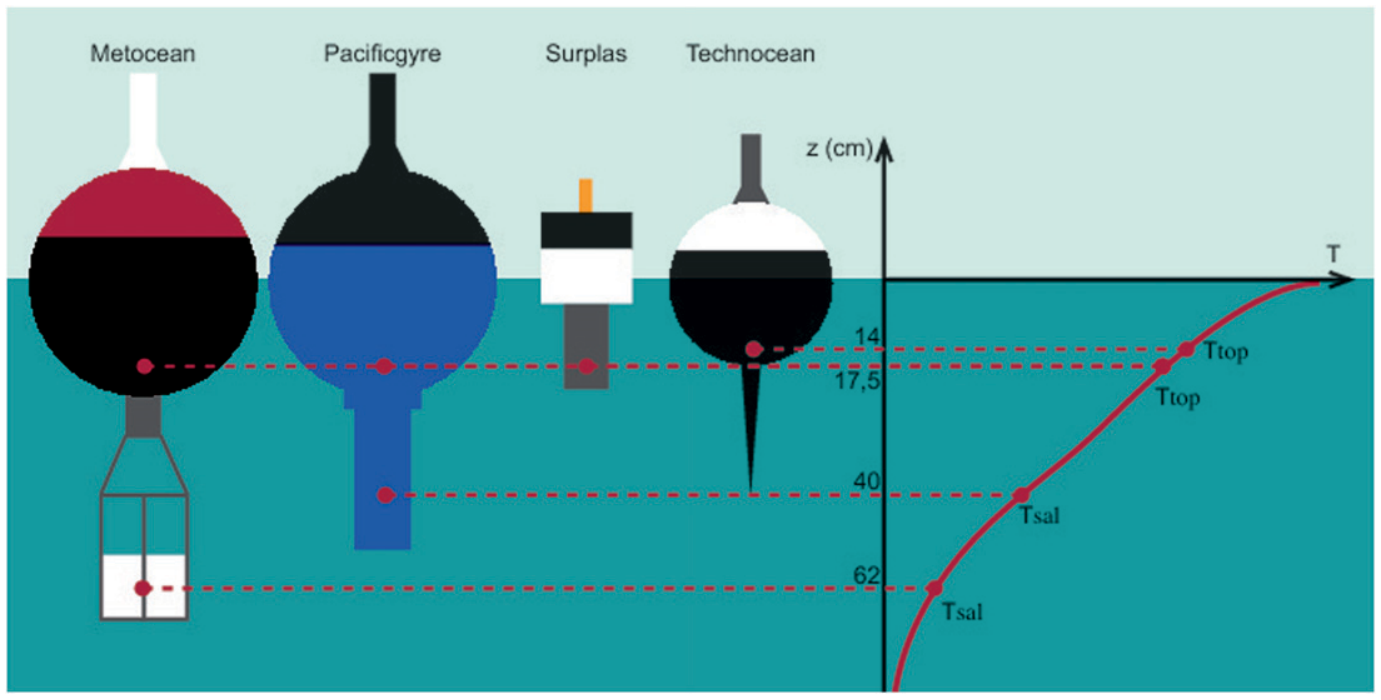

FIG. 2. Sketches of the different drifters used in this study with the position of temperature sensors. 
There are also relative errors in the changes in temperature of up to $0.01^{\circ}$ for a $2^{\circ} \mathrm{C}$ change. The temperature sensor and the way it is located did not change much during that time for each manufacturer, except for recent Pacific Gyre drifters since 2011, when the temperature sensor was changed to be more accurate and to have better thermal contact with the outside of the hull.

In addition, on the SVP-BS drifters (MetOcean and Pacific Gyre) in this study (Fig. 2), there is an unpumped SBE37 conductivity cell/thermistor $(C / T)$ unit placed underneath. Since 2007, for Pacific Gyre drifters, the conductivity cell is centered near $38 \mathrm{~cm}$ (within a tube with holes at 27 and $49 \mathrm{~cm}$ depth) and the thermistor near $43 \mathrm{~cm}$. For MetOcean drifters, the conductivity cell is near $62 \mathrm{~cm}$ (a tube with holes at 52 and $72 \mathrm{~cm}$ depth) and the thermistor is at $62 \mathrm{~cm}$. The $C / T$ data are also averaged in time (5 min on Pacific Gyre and 15 min on MetOcean) (Reverdin et al. 2007). To avoid ambiguity, these temperature measurements will be referred to as Tsal. In addition, the measured conductivity variations indicate changes either in salinity, assuming that the cell temperature is Tsal; or in the cell temperature TC, assuming that the salinity does not vary and remains equal to the morning salinity.

To validate the Ttop measurements of the SVP drifters, and to estimate near-surface stratification, we developed a small float (Surplas) with a conductivity cell and thermistor manufactured by ASD Sensortechnik GmbH (Fig. 2). This float is made of a small box with a $16 \mathrm{~cm} \times$ $13 \mathrm{~cm}$ rectangular base located $5 \mathrm{~cm}$ below the sea surface, under which the $C / T$ sensors are installed vertically. The 3.5-cm-long $C$ cell is centered at $15.5 \mathrm{~cm}$ below the sea surface and the thermistor at $17-\mathrm{cm}$ depth. The $C / T$ sensors are protected by a metal cylindrical grid $(6-\mathrm{cm}$ diameter). The float is loosely tethered to the SVP drifter with an 8-m-long light rope. Visual observations suggest that it might oscillate around its axis and can plunge vertically by up to $1 \mathrm{~cm}$ even without breaking waves. We have not measured the water flow around the float and sensors when it is towed by the SVP drifter, and thus there is some uncertainty on what it exactly measures. Because of its small size, however, we expect platform effects to be much smaller than on the larger SVP drifter. We also verified that the sensor measurement is very close to the one of temperature flowing through it, even in cases of strong insolation, as it has very good thermal contact with the seawater. Before deployments, the temperature and conductivity of these floats were checked in a bath to ensure data reliability to $0.01^{\circ} \mathrm{C}$ and $0.01 \mu \mathrm{Sm}^{-2}$, respectively. Based on postrecovery calibrations (if recovered, but also from cells kept for laboratory or cruise work), we are confident that the temperature accuracy remains within this range for the data used here. Its conductivity, on the other hand, drifts because of fouling, sometimes noticeably even over one day, so that salinity needed to be corrected. This was done based on comparisons with the measurements of the SVP-BS drifter to which it was attached.

\section{b. Drifter data}

The drifters in this study have been deployed between 2007 and 2011, either in the tropical oceans (see data distribution in Fig. 1) or in the northeast Atlantic. The tropical occurrence of large temperature daily cycles found in the data seems to provide a relatively representative sample (the drifter time series present $5 \%$ of cycles of $1^{\circ} \mathrm{C}$ or more, a very close rate compared to the $4.3 \%$ from the modeled daily cycles in Fig. 1). Some of the SVP drifters were attached to Surplas floats: Technocean SVP drifters in 2009 and 2010 (Bay of Biscay deployments) and tropical deployments of MetOcean SVP-BS drifters in 2007-09 and of SVP-BS Pacific Gyre drifters in 2007-11. The drifters often lost their drogue to which the surface buoy is tethered within 6 months after deployment. The presence of the drogue will affect the temperature measurement Ttop, as a drogue-on buoy can plunge into surface waves and there is more relative flow than when the drogue is lost. Most of the comparisons in this study correspond to the best of our knowledge to drogue-on drifters.

For Pacific Gyre drifters, we reference backward in time by $15 \mathrm{~min}$ the Ttop measurements to take into account the thermal inertia of this measurement and the time difference between the reported time and when the temperature was actually measured. No such change was required when processing the MetOcean or Technocean drifters, although introducing an additional lag of $15 \mathrm{~min}$ on the Technocean data was compatible with the data. We also correct the clock of the Surplas measurements, which was at times inaccurate by up to $15 \mathrm{~min}$ (based either on comparisons at recovery or with the Tsal and $S$ measurements of SVP-BS drifters). The final Surplas clock time is accurate to within 5 min.

\section{c. Methods}

We first remove average offsets in SVP drifter Ttop (see discussion in Reverdin et al. 2010) by adjusting nighttime temperatures [2000-0700 local standard time (LST)] of Ttop to Tsal (or for Technocean drifters, Ttop to TSurplas). We retain only days with no obvious rainfall, as can be detected from the salinity records (when available), and no sharp changes in temperature or salinity, which could be indicative of crossing a front (which is checked visually). This assumes that at night there are no vertical gradients in the 

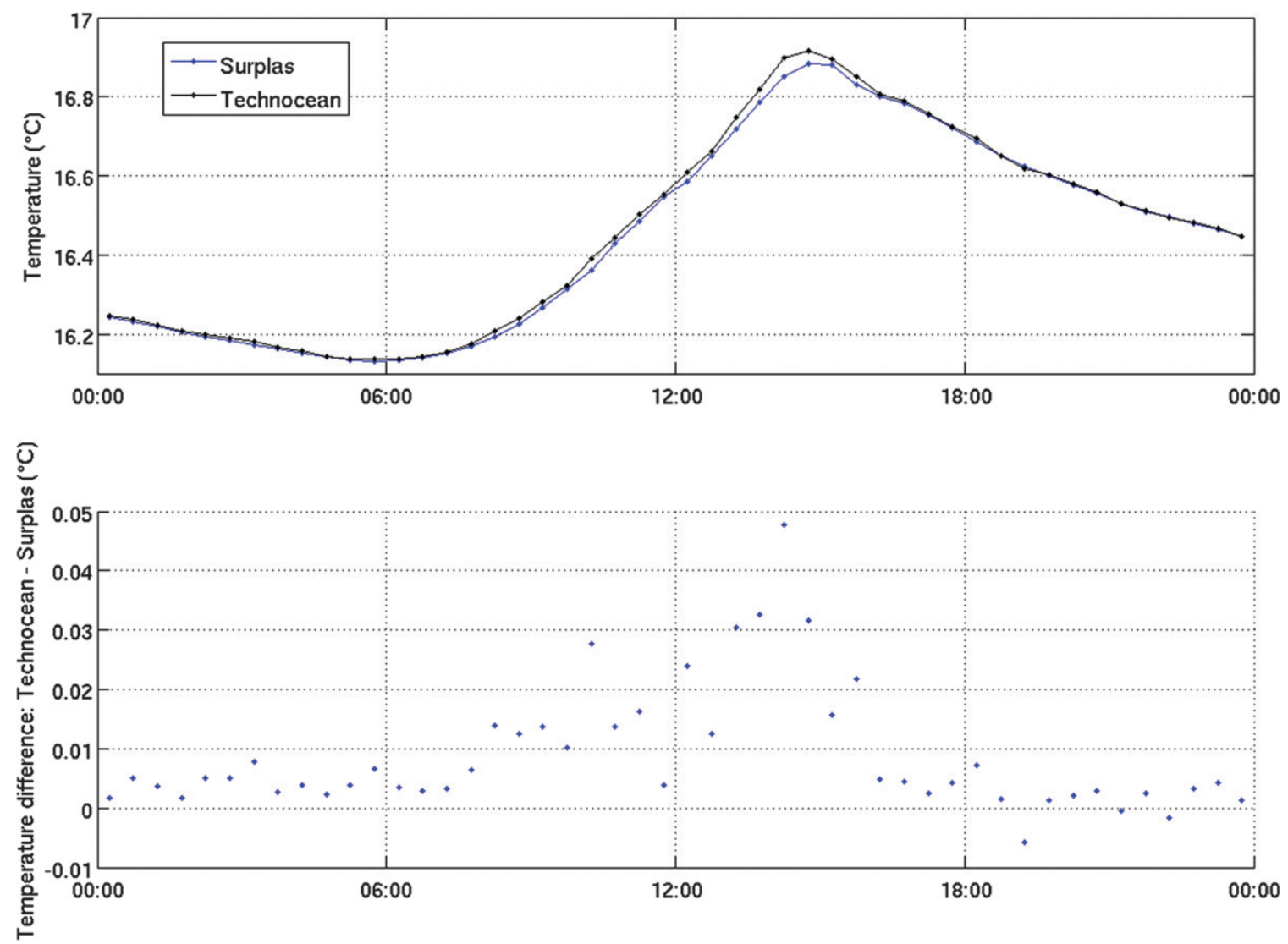

FIG. 3. Comparison of daily cycles (LST) of temperature Ttop from Technocean drifters with the temperature TSurplas from the Surplas floats: average (top) cycles and (bottom) difference Ttop - TSurplas over 148 days.

upper layer between a few centimeters from the surface to roughly $1 \mathrm{~m}$, a reasonable assumption in view of the much larger than expected daytime gradients; however, it could at times introduce errors of a few $0.001^{\circ} \mathrm{C}$. We also require that there are no missing data for that day. With these conditions, we retain roughly 8000 days of SVP-BS drifters and 148 days of Technocean SVP drifters.

Time is then adjusted each day, so that noon corresponds to the highest sun elevation (closest half hour) and the individual daily cycles are combined to provide an average comparison in local sun time (LST). We characterize the daily variability for a given day by an amplitude estimated as the difference between the maximum daily temperature and the early morning minimum temperature. When comparing two temperature records (from the same drifter or from attached drifters), we typically find a large noise in individual comparisons. To reduce this noise, we often average the differences between the two records from 1000-1600 LST to characterize the "warm" portion of the day. Most times, this averaging encompasses the daily maximum surface temperature. Vertical temperature stratification is often weak at 1600 LST and the 1000-1600 LST average reduces maximum stratification by $25 \%$ based on their average daily cycle curve. The daily differences will often be presented in scatterplots as a function of this daily cycle amplitude. When possible, regression polynomials will be fitted to these distributions of daily estimates. In certain instances, data will be grouped and averaged in classes of daily amplitude in Ttop.

\section{Daytime temperature measurements of SVP drifters}

\section{a. Comparisons with Surplas temperatures at $17 \mathrm{~cm}$}

We will first compare the Ttop data of the SVP drifters with the temperature measured at $17-\mathrm{cm}$ depth by the Surplas floats. For Technocean drifters, all comparisons (148 days) were done in late spring 2009 and 2010 in the Bay of Biscay, with often weak wind $\left(16 \%,<4 \mathrm{~m} \mathrm{~s}^{-1}\right.$, and median wind of $6.2 \mathrm{~m} \mathrm{~s}^{-1}$ ) and a large average daily cycle $\left(0.7^{\circ} \mathrm{C}\right.$ peak to peak) (Fig. 3). The average difference, Ttop - TSurplas, is fairly small but with larger daily cycles in Ttop than in TSurplas. This difference averaged between 1000 and 1600 LST is on the order of 


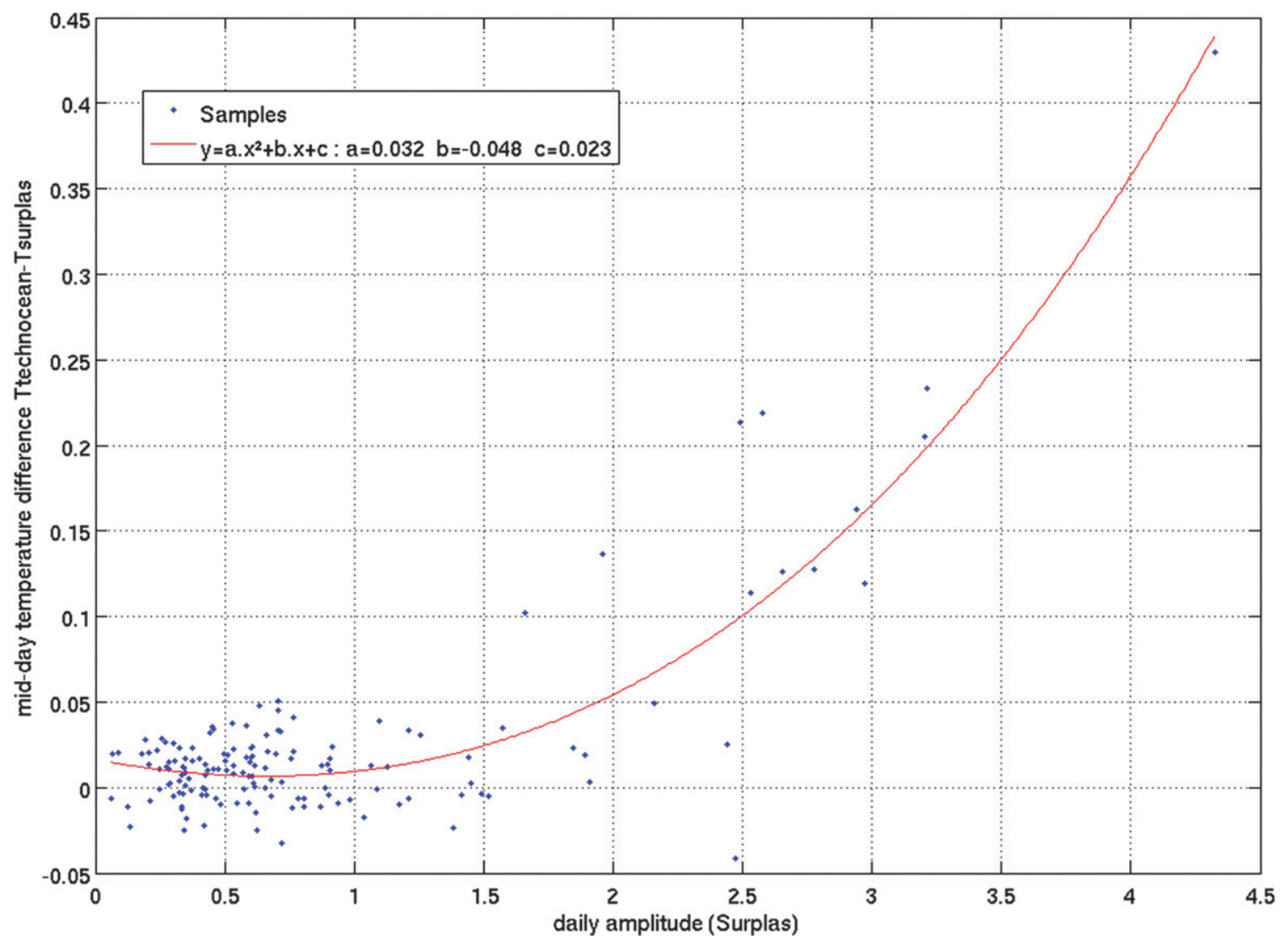

FIG. 4. Comparison of Ttop and TSurplas. Scatter of midday temperature difference Ttop - TSurplas (averaged between 1000 and 1600 LST) as a function of daily peak-to-peak amplitude of TSurplas.

$3 \%$ of the peak-to-peak temperature range. When considering individual daily cycles (Fig. 4), it appears that there is a large scatter of the temperature differences; and that the dependency of the difference is not linear. It probably reaches $>5 \%$ at a value of $3^{\circ} \mathrm{C}$ (but only on one day), but is usually $<2 \%$ for a daily cycle amplitude $<1.5^{\circ} \mathrm{C}$. There is a large data scatter for amplitudes of $1^{\circ} \mathrm{C}$ or less, but the difference remains positive for the small daily cycles that correspond mostly to windy situations, even though during such days the floats are expected to plunge often under the surface and sample the deeper levels.

For MetOcean SVP-BS drifters, which have a larger sphere $(41 \mathrm{~cm})$, the comparisons (36 days, not shown) are from Surplas drifters in the western tropical Atlantic in 2007-09, often for cloudy days and sustained trade winds. The average daily cycle in this comparison is small $\left(0.18^{\circ} \mathrm{C}\right)$; the average daily cycle of Ttop - TSurplas is $<3 \%$ peaking near noon with a significant $(95 \%)$ nonzero average of $0.005^{\circ} \mathrm{C}$ between 1000 and $1600 \mathrm{LST}$. (Because of the low reported resolution, the uncertainty of the hourly average for the daily cycle is on the order of $0.007^{\circ} \mathrm{C}$; , and thus on the order of $0.0025^{\circ} \mathrm{C}$ for the 1000 1600 LST averages).

For Pacific Gyre drifters, we have a larger set of comparisons from the three tropical oceans but mostly from the equatorial Atlantic and Indian Oceans, both for the drifters manufactured until 2010 and for the ones with a change in thermistor since then. Thus, the comparison is made separately for two sets of drifters, the ones deployed before 2011 (114 days) and the ones deployed in 2011 and 2012 (74 days). In the first set, we can group the comparisons by classes of daily cycle amplitudes. The histogram of those shows, however, that there is a majority of days with cycles less than $0.25^{\circ} \mathrm{C}$ and 9 and 4 days with amplitudes larger than $0.8^{\circ} \mathrm{C}$ (for drifters before and since 2011, respectively). The average daily cycle in Ttop is on the order of $0.25^{\circ} \mathrm{C}$, with the average daily cycle in the difference, Ttop TSurplas, on the order of $0.019^{\circ} \mathrm{C}$ (with uncertainty on the order of $0.001^{\circ} \mathrm{C}$ ). The effect seems less for the more recent drifters, as can be identified in the scatterplot of the differences (averaged 1000-1600 LST), as a function of the daily cycle amplitude (in TSurplas) (Fig. 5). 


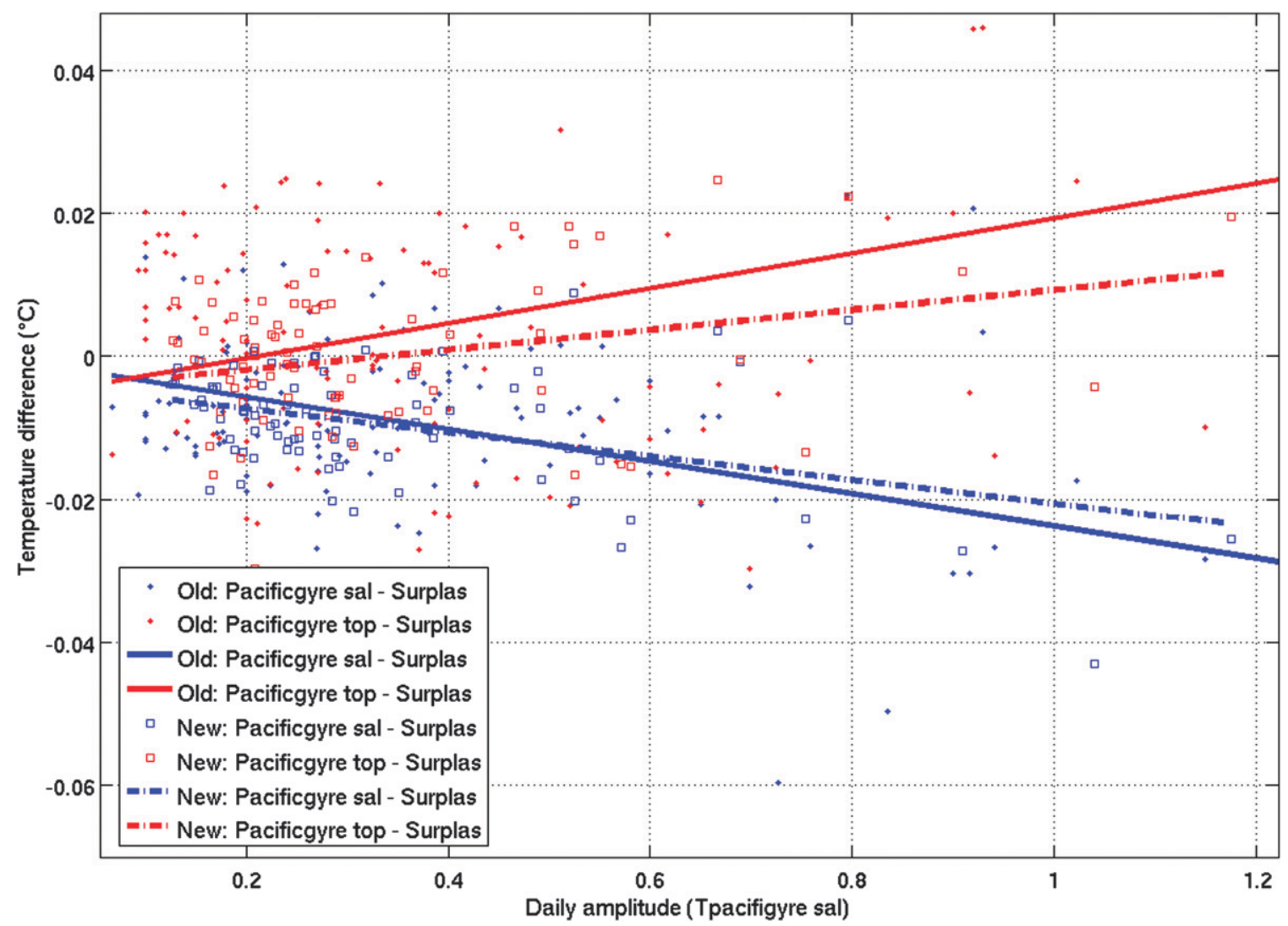

FIG. 5. Scatterplot of difference Ttop - TSurplas (red) and Tsal - TSurplas (blue) averaged between 1000 and 1600 LST as a function of daily peak-to-peak temperature amplitude from the Pacific Gyre model before 2011 (old, solid lines) and the model since 2011 (new, dashed lines).

However, part of the differences in Tsal - TSurplas between the old and the newer drifter model could be related to differences in sampling (seasons, regions, etc.), and whether these significances are significant thus cannot be asserted. A linear regression line is shown both for the old and new models on a scatterplot of individual temperature differences (averaged 1000-1600 LST) as a function of daily cycle (Fig. 5). For the weak daily cycles, it appears that midday Ttop - TSurplas is slightly negative, by $-0.005^{\circ} \mathrm{C}$. These small daily cycles likely correspond to windy situations, for which we expect that the sphere plunges often in the waves as it is towed by its drogue, and thus the actual depth of the sensor might be deeper than the $T$ sensor of the Surplas that floats at the sea surface. Another contribution is from the thermal inertia and the 30-min averaging in the Ttop measurements for these drifters that will slightly reduce the amplitude of the daily cycle (and the 1000-1600 LST difference). This underestimate at low daily cycle amplitudes was not present for Technocean drifters (Fig. 4), which have slightly smaller spheres but which should also plunge in the waves.

The scatterplot (Fig. 5) suggests a dependency of the temperature difference (averaged between 1000 and 1600
LST) with a daily amplitude of $2 \%$ for the old model and $1 \%$ for the new model. The change in the amplitude between the older and the more recent models might result from the change in sensor and its thermal contact, and thus this could be associated with different platform effects. However, it may not be significant because of the different stratification conditions encountered (Fig. 5). Also, this did not sample situations with a very large daily cycle for which this linear relationship would be less likely to hold, based on what was found for Technocean drifters (Fig. 4).

\section{b. Platform effects}

The differences illustrated between Ttop and TSurplas suggest platform effects. This could be related, either from an influence on the measurement of internal drifter temperature or from an influence of flow around the drifter in the presence of stratification in the upper $20 \mathrm{~cm}$ of the water column, at least for the large diurnal cycles.

In an earlier study (Reverdin et al. 2010), we had illustrated that the initial Ttop measurements are influenced by the drifter internal temperature. This may depend on the drifter type. For example, comparisons 

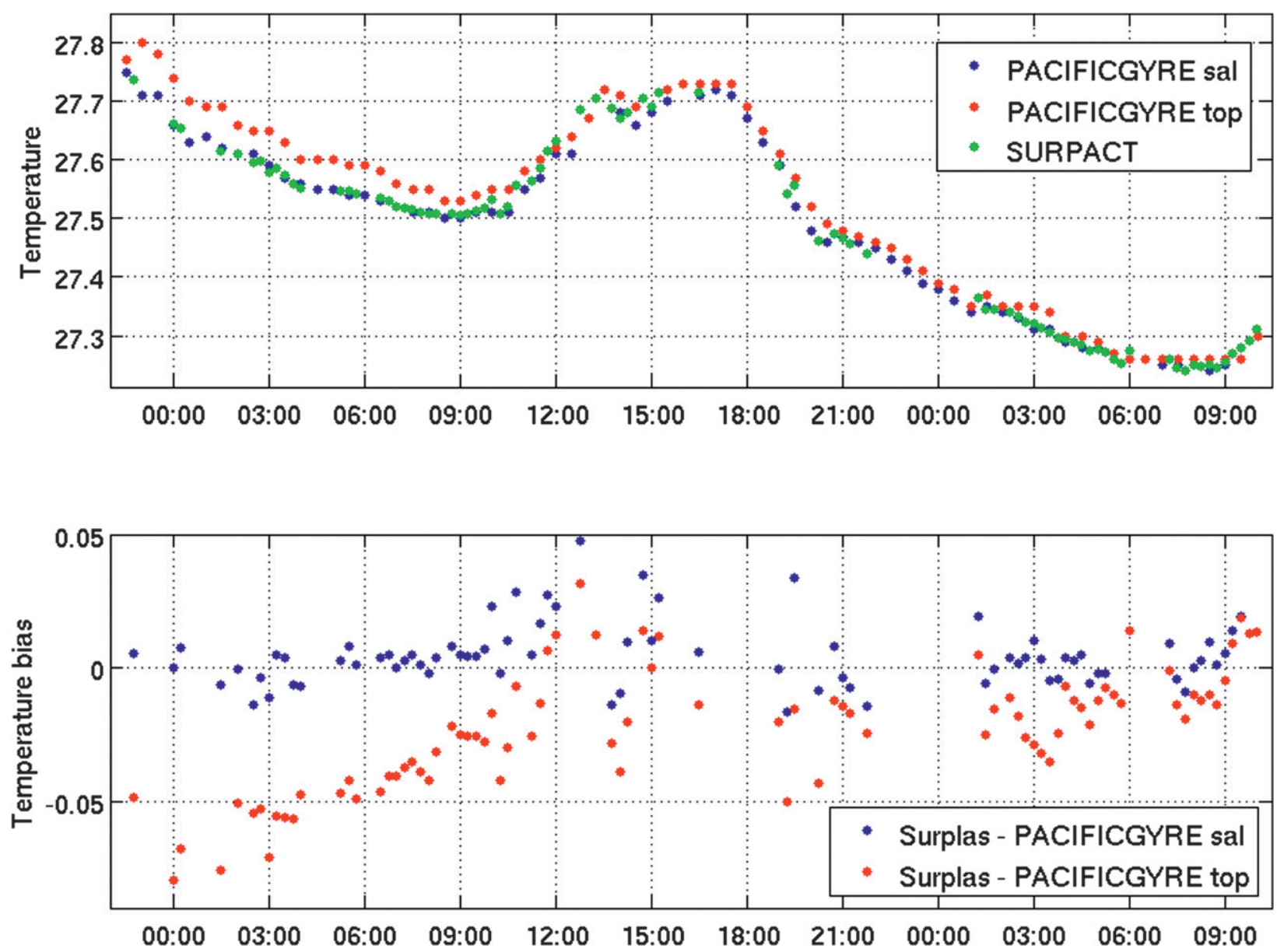

FIG. 6. First two days after deployment of Pacific Gyre 109456 with a prototype float labeled Surplas in the equatorial Atlantic $\left(0^{\circ}-23^{\circ} \mathrm{W}\right.$, 23 Mar 2012). (top) Comparison of TSurplas (measured at $4 \mathrm{~cm}$, black diamonds) with Ttop (red diamonds and Tsal (blue diamonds). (bottom) Temperature differences TSurplas - Ttop (red diamonds) and TSurplas - Tsal (blue diamonds).

with TSurplas at deployment suggest a difference between the old and recent models of SVP-BS Pacific Gyre drifters, with the new sensor being in better thermal contact with the seawater. However, even this new model shows an influence of internal temperature for almost $12 \mathrm{~h}$ after deployment (e.g., in Fig. 6). In this case, there was probably a very large warming of the drifter (by a few degrees Celsius) before deployment. In ocean situations and because of the adjustment time scale, we expect that the effect on the internal temperature variability on the Ttop daily cycles will remain small compared to what is observed. This is, of course, an assumption that will have to be validated with other data and in situ temperature measurements.

In the following, we will investigate possible stratification in the top 20 -cm layer, and for that we examine the daily cycle in $C$ measured at $15.5-\mathrm{cm}$ depth on the Surplas drifters, removing the $C$ variations associated with TSurplas at $17-\mathrm{cm}$ depth. This residual conductivity $\left(C^{\prime}\right)$ results from both salinity variations at $15.5 \mathrm{~cm}$ and the difference between the cell temperature and $17 \mathrm{~cm}$ (TSurplas). When considering only daily cycles when the drifter was away from a front and those that have large daily TSurplas cycle $\left(2^{\circ} \mathrm{C}\right.$ or more, averaging $2.2^{\circ} \mathrm{C}$, corresponding mostly to the ones attached to Technocean drifters), we find larger $C^{\prime}$ in midday between 0000 and $1400 \mathrm{LST}$ by $0.20 \mu \mathrm{S} \mathrm{cm}^{-2}$. This increase in $C^{\prime}$ can be either related to an increase of $S$ by roughly 0.11 psu or to a temperature difference of TC - TSurplas $=0.06^{\circ} \mathrm{C}$. For these days with low wind, evaporation should at the highest be $0.3 \mathrm{~mm}$ in $6 \mathrm{~h}$ (based on flux data from the 2009 Gogasmos cruise in the Bay of Biscay, during which some of the large daily cycles took place). If this evaporation was distributed over $20 \mathrm{~cm}$, then the maximum salinity change would be 0.05 psu. Thus, at least half of the $C$ change should be interpreted as temperature stratification between 15.5 and $17 \mathrm{~cm}$. On the Self-Contained Autonomous Microprofiler (SCAMP) profiles collected during large daily cycles at the same time as the Surplas data in the Bay of Biscay in particular on 12 May 2009, we also observed 
gradients of $0.1^{\circ} \mathrm{C}$ over a distance of $1.5 \mathrm{~cm}$, thus in the same range as what is implied by the Surpact $C$ data. Based on these estimates and what we found in the difference with the Technocean Ttop, Ttop could be close on those days of large cycles to the temperature near $13-15 \mathrm{~cm}$, which is roughly the sensor depth for that kind of "small sphere" SVP drifter. This does not, however, explain the small warming for the weak daily cycles.

Using this stratification information for the SVP-BS Pacific Gyre drifter is more uncertain, as the Pacific Gyre drifters are in different areas (and not enough joint Surplas-SVP data for the $>0.8^{\circ} \mathrm{C}$ daily cycles of Fig. 5). The data do, however, suggest a small platform effect for the Pacific Gyre drifters on the order of $1 \mathrm{~cm}$ (thus $16 \mathrm{~cm}$ ) for the new model or $2 \mathrm{~cm}$ (thus $15 \mathrm{~cm}$ ) for the older model. However, this is but a small part of the daily cycle amplitude; and the Ttop data should be helpful in estimating near-surface daily temperature cycles as was done, for example, in Bellenger and Duvel (2009).

\section{Temperature stratification from SVP-BS drifters}

We found in the previous section that the actual equivalent depth of the Ttop measurement on SVP-BS drifters is a little shallower than the expected $17-\mathrm{cm}$ depth, and that there are some uncertainties in it. It should, however, remain useful for estimating nearsurface stratification. To verify that, we compared Ttop with the other measurements of the MetOcean and Pacific Gyre SVP-BS drifters, in particular Tsal.

We will first present the differences between the two measurements, Ttop and Tsal. The average daily cycles of these two measurement have close amplitudes (for the Pacific Gyre drifters, and even more for the MetOcean drifters there is a vast majority of cases with daily cycles less than $0.5^{\circ} \mathrm{C}$ ) (Fig. 7). However, the difference between Ttop and Tsal has a significant daily cycle with the same shape for both types of drifters. The average difference peaks in the middle of the day or slightly after (near 1245 LST for Pacific Gyre and 1330 LST for MetOcean drifters), which is earlier than the time of peak temperature (1430 and 1500 LST, respectively; Fig. 7). Values of the average differences are larger for MetOcean, even though the average daily cycle amplitude is less. When considering the scatterplot of midday temperature differences versus daily cycle amplitudes, we expect a dependency on daily insolation values, as the midday stratification is a function of both wind and insolation (Gentemann et al. 2009). Despite the small number of large daily cycles, we can get a first-order estimate of this dependency in these data by separating data for midday sun elevations higher than $65^{\circ}$ from data with a lower sun elevation. We also separated data within the tropics $\left(25^{\circ} \mathrm{N}-25^{\circ} \mathrm{S}\right)$ from the ones at higher latitudes. To first order, the results are similar in the two domains, and we will mostly comment on the more robust results for the tropical domain (Fig. 8). The shapes of the temperature difference curves are all similar, with a fast parabolic-like increase for daily cycle amplitudes $>2{ }^{\circ} \mathrm{C}$. The temperature differences are less for Pacific Gyre than for MetOcean; this is in keeping with the smaller vertical separation between the two sensors for the former $(26 \mathrm{~cm})$ than for the later $(45 \mathrm{~cm})$ drifter. At a given daily cycle amplitude, the stratification is also higher for low-sun elevation than for high-sun elevation. This is expected because for a given daily cycle amplitude, the lower sun elevation (thus insolation) should be associated with less wind, and thus less mixing and more stratification. This stratification corresponds to a significant percentage of the total daily cycle amplitude and increases rapidly for increasing amplitudes: for example for a $1^{\circ} \mathrm{C}$ amplitude, it is in the range of 3\%-5\% for the Pacific Gyre drifters and 6\%-10\% for MetOcean drifters (the lower values are for the high-sun elevation category). It is important to notice that these differences are much larger than the ones found in section 3 between Ttop and the Surplas measurements at $17 \mathrm{~cm}$. These results include both drifters with a drogue and drifters without a drogue. In the future, it would be interesting to separate the two categories, which could have different characteristics of the Ttop measurement, but the statistics were not sufficient for that here.

We further investigated this difference in the daily cycle close to the surface and deeper by considering the Pacific Gyre drifters, where there is a slight shift in immersion between the conductivity cell and the Tsal measurement, which can be used to infer more quantitative information on stratification near $40 \mathrm{~cm}$. We will concentrate on tropical drifters and we also include two classes depending on sun elevation, as done for Fig. 8. We found that it was necessary to average the data by class of daily cycle amplitude to get reliable estimates (high and low sun elevation, respectively): the bins retained are $1^{\circ}-1.5^{\circ} \mathrm{C}(24$ and 6 days $), 1.5^{\circ}-2.5^{\circ} \mathrm{C}(11$ and 7 days), and over $2.5^{\circ} \mathrm{C}$ (5 and 1 days). The results of the comparisons are presented in Fig. 9. In the middle panel, salinity is estimated from conductivity assuming that $\mathrm{TC}=$ Tsal, which illustrates unrealistically large cycles in $S$ [as was already commented on by Reverdin et al. (2007)], at least by a factor of 4 . The other simplification is to assume $S$ constant (the morning salinity) and derive from $C$ a temperature TC, and then a gradient TC Tsal. In order to scale this to the layer depth between the Ttop and Tsal levels, we use the relation $5 \times(\mathrm{TC}-$ Tsal). The factor 5 is to scale gradients over distances over $25 \mathrm{~cm}$, assuming a $5-\mathrm{cm}$ difference between the $C$ and Tsal sensors, compared to the $25 \mathrm{~cm}$ between the height 

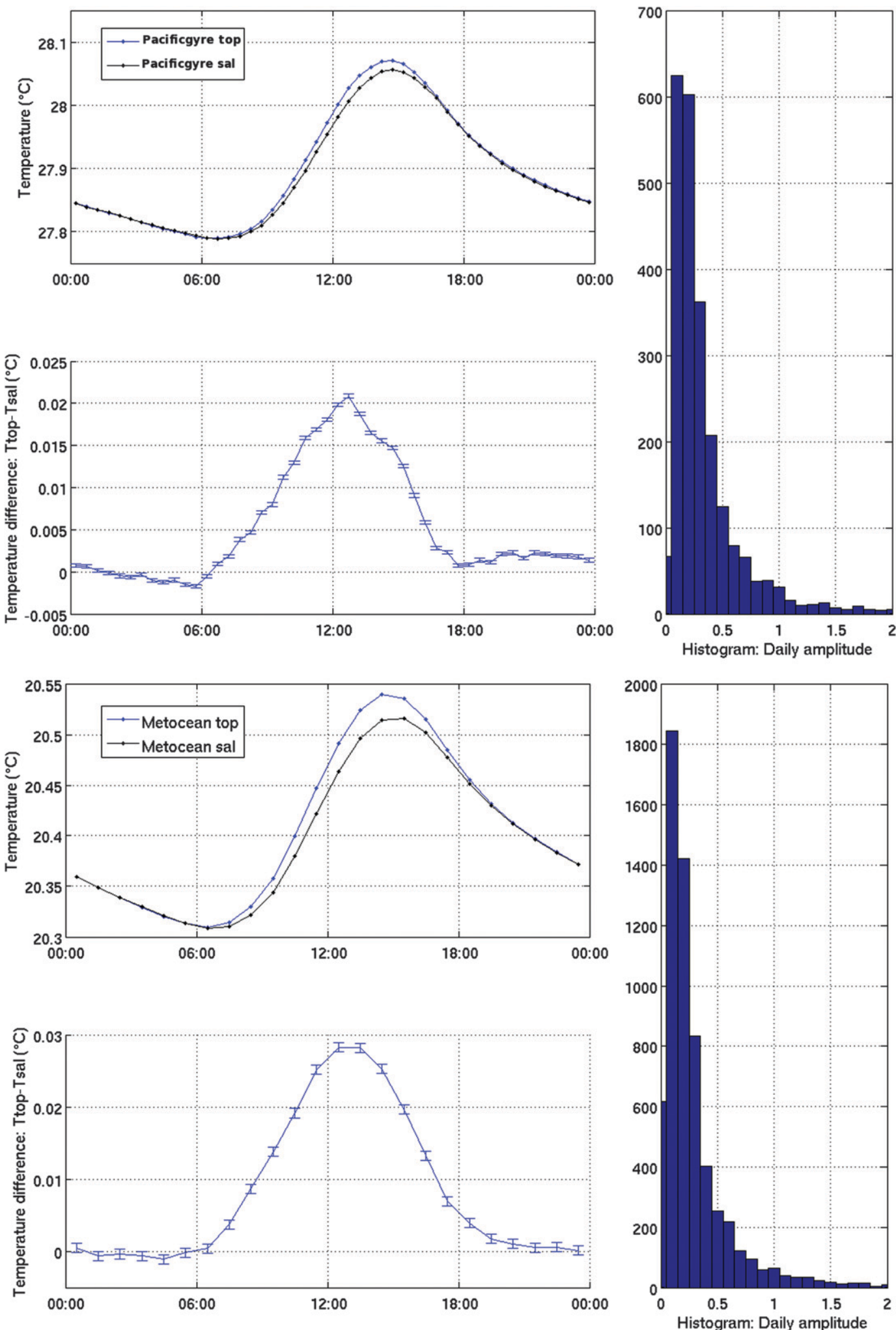

FIG. 7. (left) Average daily cycles of (top) Ttop (black) and Tsal (blue) and (bottom) Ttop - Tsal, with (right) histogram of the individual occurrences of daily amplitudes: (top two panels) Pacific Gyre and (bottom two panels) MetOcean drifters. One standard deviation error bars are shown for the temperature differences. 

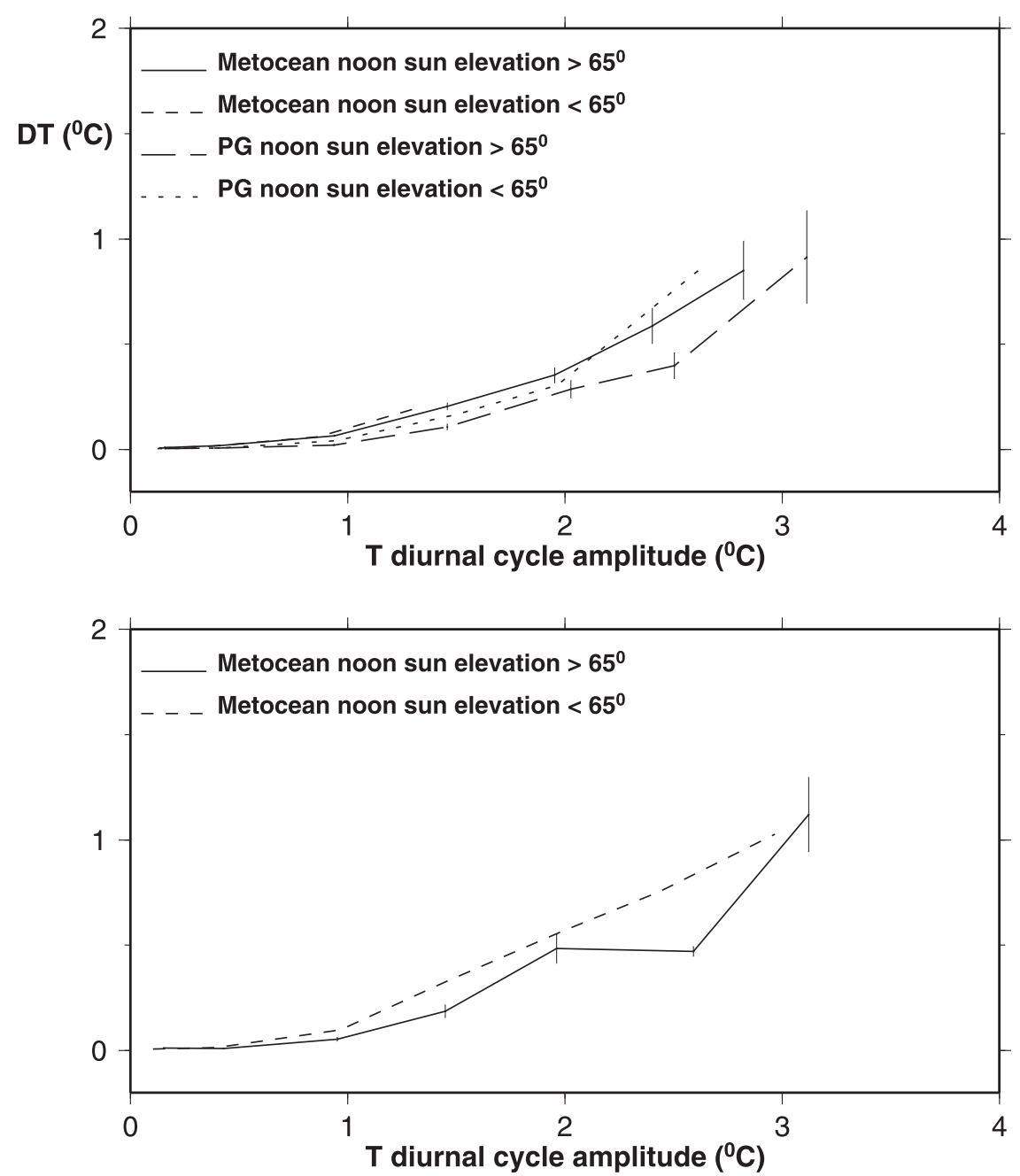

FIG. 8. The DT $=$ Ttop - Tsal (averaged 1000-1600 LST) as a function of diurnal cycle amplitude for two classes of sun midday elevation less than and greater than $65^{\circ}$ for MetOcean and PG SVP-BS drifters; (top) tropics $25^{\circ} \mathrm{N}-25^{\circ} \mathrm{S}$ and (bottom) $25^{\circ}-60^{\circ} \mathrm{N}$, MetOcean only. The vertical bars are one standard deviation error bars indicated only for the high-sun elevation classes.

of Ttop and Tsal. The $5 \times(\mathrm{TC}-\mathrm{Tsal})$ curve systematically peaks a little later than (Ttop - Tsal) and regularly has larger values. This is particularly pronounced for the $2.5^{\circ}-4^{\circ} \mathrm{C}$ and high midday sun elevation case, with the suggestion that stratification near $40 \mathrm{~cm}$ was $30 \%$ larger than for Ttop - Tsal near 1500 LST, whereas it is nearly identical near 1000 LST or noon. This, however, includes also a small contribution of a neglected salinity increase to the gradient estimate near $40 \mathrm{~cm}$, when there is no upper-temperature gradient left (see middle panel in Fig. 9 with late afternoon $S$ for the high-sun elevation category). There are also differences between the highsun and the low-sun elevation classes. The temperature difference curves are larger in the morning with lowsun elevation than for later in the day in the high-sun elevation class. The difference TC - Tsal is also smaller for the low-sun elevation class than it is for the high-sun elevation class.

These results on stratification near $40 \mathrm{~cm}$ or a little deeper can be checked by combining the Pacific Gyre Tsal data at $43 \mathrm{~cm}$ with the Tsal data at $62 \mathrm{~cm}$ of the MetOcean drifters. We retain only MetOcean data in the tropics and with nearly similar daily cycle amplitudes, thus constructing pseudo-profiles at different times of day with the additional 62-cm-depth Tsal measurement of the MetOcean drifter. We find for the $1.5^{\circ}-2.5^{\circ} \mathrm{C}$ case (18 Pacific Gyre days and 18 MetOcean days) a gradient between 43 and $62 \mathrm{~cm}$ (Fig. 10) that is of similar magnitude to what is found near $40 \mathrm{~cm}$. On the other hand, at 1700 LST, gradients near $62 \mathrm{~cm}$ are much weaker, indicating that vertical mixing penetrates to this depth. In the morning or early afternoon, there is also a suggestion of slightly larger gradients in the 

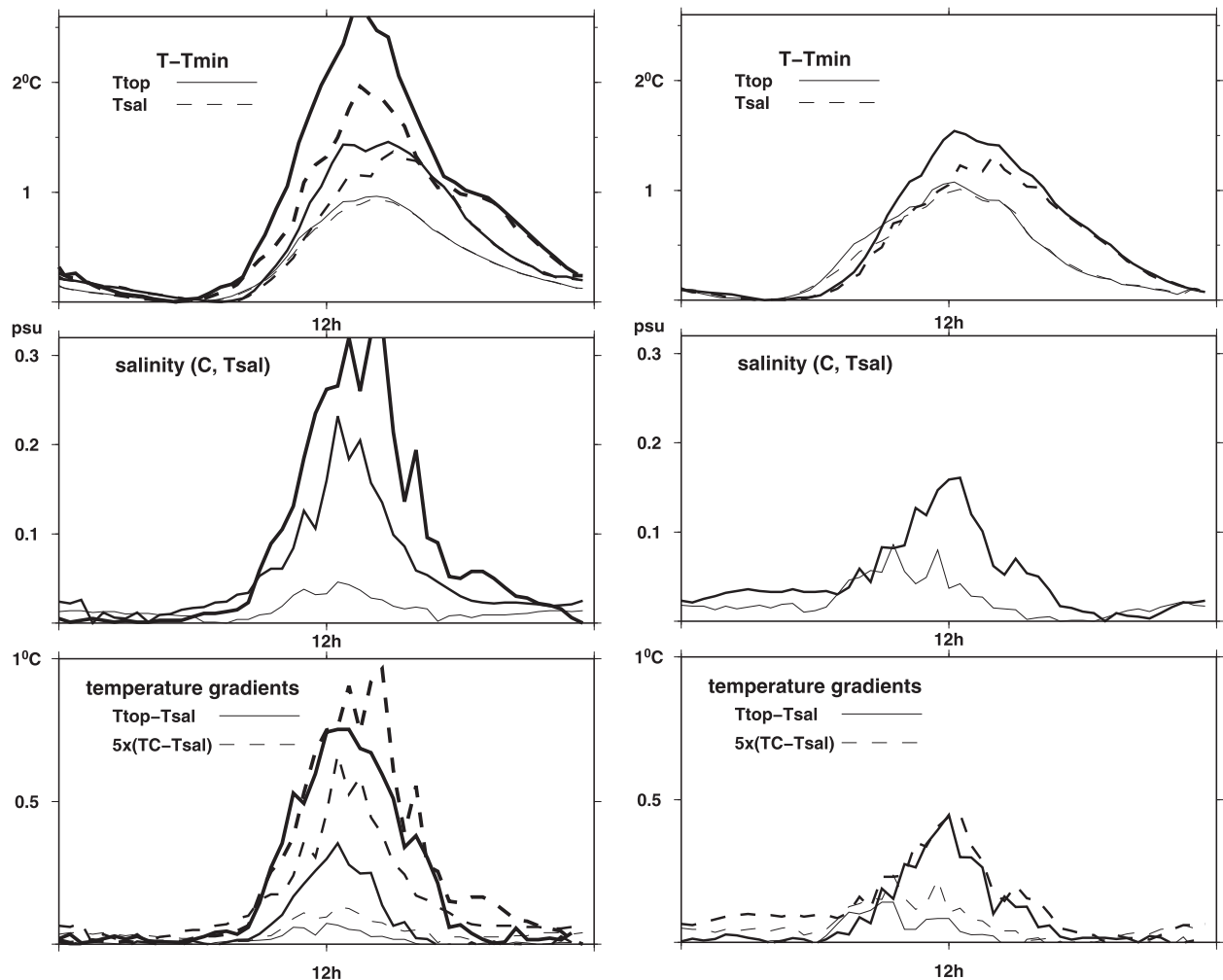

FIG. 9. Average diurnal cycle from Pacific Gyre drifters in the tropics sorted by classes of daily amplitudes $\left(1-1.5^{\circ}, 1.5^{\circ}-2.5^{\circ}\right.$, and $>2.5^{\circ} \mathrm{C}$; thicknesses of lines increases with increasing amplitude: (left) (top) Ttop and Tsal, (middle) $S$ estimated from $C$ and assuming $T=$ Tsal, and (bottom) comparison of Ttop - Tsal and $5 \times$ (TC - Tsal), where TC is estimated from $C$ assuming $S$ constant for midday sun elevation $>65^{\circ}$. (right) As in (left), but for lower sun elevations.

deeper part (39-62) than between 17 and $39 \mathrm{~cm}$. We do not have enough cases of daily cycles larger than $2.5^{\circ} \mathrm{C}$ in MetOcean drifters to invalidate the larger afternoon gradient near $40 \mathrm{~cm}$ found with Pacific Gyre drifter data in Fig. 9.

\section{Discussion}

We presented in section 4 statistical estimates of stratification in the upper $62 \mathrm{~cm}$ based on the drifter sensors of different models of SVP-BS drifters. The data

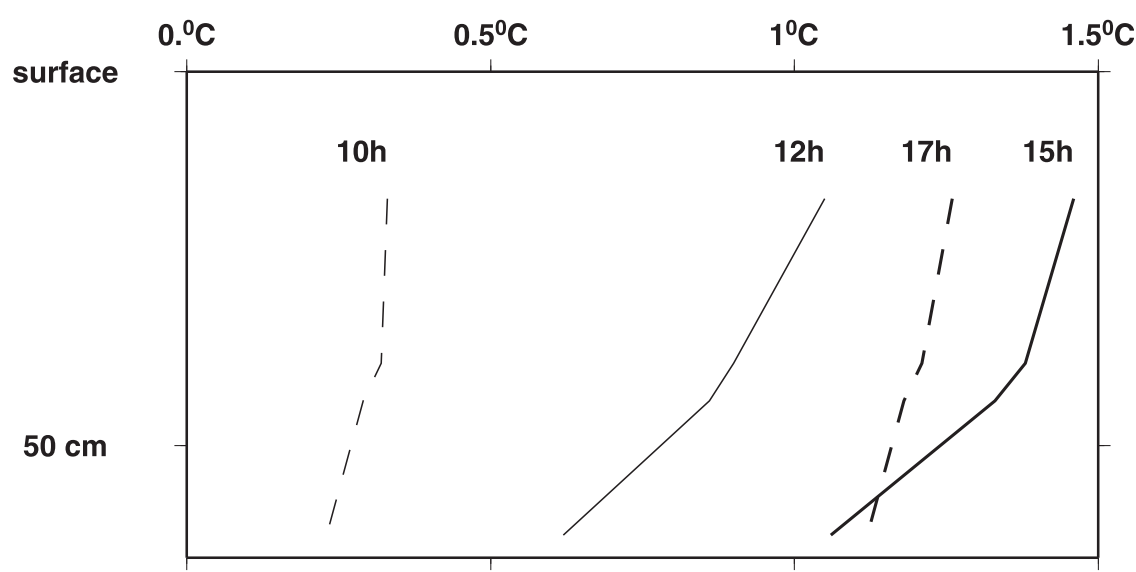

FIG. 10. Average daily warming tropical-ocean profiles for between $1.5^{\circ}$ and $2.5^{\circ} \mathrm{C}$ at 1000,1200 , 1500 , and 1700 LST. The estimate at $62-\mathrm{cm}$ is based on the MetOcean data with Ttop normalized to the average of the Pacific Gyre drifters (old model). Only the cases with midday sun elevation $>65^{\circ}$ are included. 
suggested different shapes of the profiles in the morning and afternoon for the large daily cycles within this upper-62-cm layer of the ocean, with weaker gradients in the top $62 \mathrm{~cm}$ in the late afternoon (1700 LST). These results were based on combining data that are not on the same platforms, and thus that could have encountered different conditions affecting the stratification (e.g., waves, swells, insolation, and water optical properties). Nonetheless, all the information collected suggests significant stratification in this layer for large daily cycles.

This investigation of vertical temperature stratification uses the Ttop measurement from the SVP drifters. The comparison with Surplas float measurements indicated that for large daily cycles, the top measurements of SVPBS drifters have larger daily cycles than TSurplas at $17 \mathrm{~cm}$. This consideration, however, is based on a toosmall sample for the MetOcean drifters with very weak daily cycles, and for a sample limited to daily cycles less than $1.2^{\circ} \mathrm{C}$ for the Pacific Gyre drifters. From these limited data, we expect possible differences on the order of $1 \%-2 \%$ for a $1{ }^{\circ} \mathrm{C}$ daily cycle amplitude, and more for very large daily cycles (but not measured). Surplas data suggest temperature stratification near $17-\mathrm{cm}$ depth during those cycles that could explain the differences in daily cycle if the SVP-BS hull temperature Ttop corresponds to a shallower water origin than $17 \mathrm{~cm}$. This was even more noticeable for the Technocean (small) SVP drifters, for which we could attribute a depth of $13-15 \mathrm{~cm}$ to the Ttop measurement, close to the actual sensor depth. There is, however, also the possibility of internal temperature influence on Ttop. In the future, measuring internal drifter temperature should be done in order to separate the platform effect, which results from thermal contact with the drifter's hull, from the effect of how the water flows around the top sphere and reaches the sensor. Although here we considered mostly drifters with their drogue attached, it is important to be reminded that the platform effect will be sensitive to the loss of the drogue. Indeed, we expect undrogued drifters to be less immersed than drogued drifters, and thus warming more during daytime with a slightly shallower sensor depth. Both with Pacific Gyre and MetOcean drifters that we use, the temperature sensors are now expected to be more accurate and more stable in time, which should make these comparisons less subject to possible methodological flaws. A suggestion for future drifter designs might be to extend the length of the sensor away from the drifter hull, thereby reducing platform mixing and allowing for the determination of extreme temperature gradients (e.g., $>10^{\circ} \mathrm{C} \mathrm{m}^{-1}$ ) under very low wind conditions.

Thus, current limitations on investigations of nearsurface stratification from drifters originate from the following: (i) Platform effects that will be particularly important for the Top measurement. We found suggestions that different sensors or drifter designs result in different platform effects. Notice that this evaluation (comparison to Surplas floats) does not incorporate cases of very large daily cycle amplitudes in the tropics. Platform effects will also be large for the lower sensors, and in particular our interpretation of the conductivity measurements of the SeaBird $C / T$ sensors suffers from the lack of clear separation between the salinity and temperature gradient contributions. The salinity contribution is clearly smaller, except maybe in the late afternoon; however, the conductivity cell is a long tube, for which we do not know what the average temperature is, in the presence of little wind-waves and strong temperature stratification. There is also the possibility that the motions of the platform can induce mixing, limiting the ability to measure the true stratification.

(ii) To get a temperature profile, we merged data of different origins, which could have witnessed different insolation-wind-sea-state conditions. Also, there is little vertical resolution in these average profiles. Our investigation also excluded cases of very large surface daily cycles, which could have different profiles (see appendix).

(iii) The inertia of the measurements by the upper sensor with respect to time is large. This was roughly but only approximately corrected and could result in fairly large errors in the temperature gradient estimates during the morning.

For (i), autonomous profilers specifically designed to minimize flow perturbation and measurement accuracy would provide an independent assessment of profile shape and drifter Ttop measurements. There were profiles indicating very large near-surface gradients in large daily cycles during the May 2009 Gogasmos cruise, which Technocean-Surplas drifters were deployed. Such large gradients have also been regularly found under conditions of low wind and high insolation with data from SkinDeEP. SkinDeEP is an upwardly rising profiler that is equipped with a fast-responding FP07 thermistor, allowing it to make temperature profiles over the upper $10 \mathrm{~m}$ of the ocean with a spatial resolution of $O(1 \mathrm{~mm})$. From this continuous profile dataset, we can extract data from any depth in the water column and investigate gradients. Figure 11 shows gradients between depths of 14 and $17.5 \mathrm{~cm}$ as a function of local time. These data are from three separate field experiments: the Gulf of California (Ward 2006), the equatorial Pacific (Ward et al. 2004b; McGillis et al. 2004), and the Mediterranean (Ward and Fristedt 2008). Although 


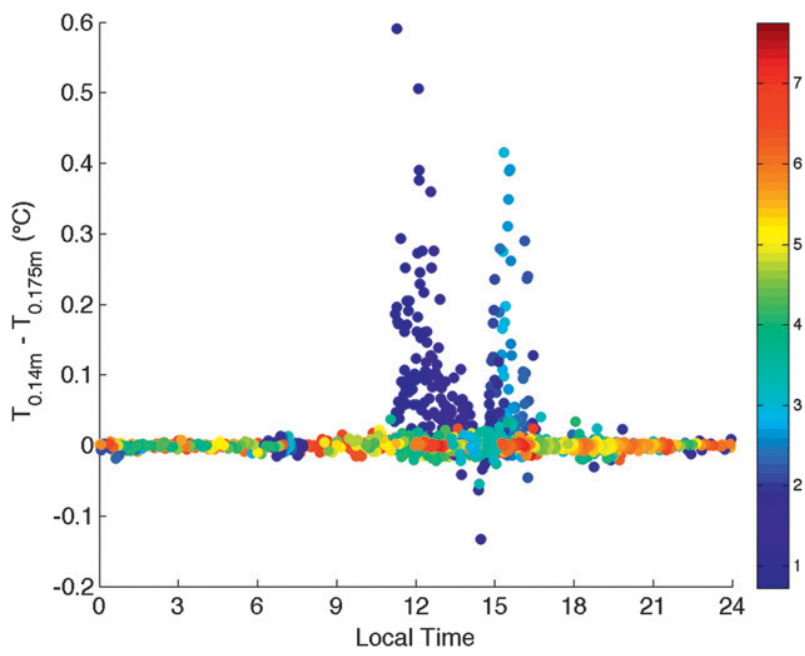

FIG. 11. Measurements of gradients between the two depths (corresponding to Ttop and Tsal) as a function of local sun time taken with SkinDeEP during the three separate field experiments listed in the inset. Color bar represents the wind speed (range 0.7$7.7 \mathrm{~m} \mathrm{~s}^{-1}$ ) for these measurements.

there is evidence of extreme gradients over this $3.5-\mathrm{cm}-$ depth range, $96 \%$ of the data have gradients $<0.1^{\circ} \mathrm{C}$. Of the remaining $4 \%$ of the data, where the temperature gradient are $>0.1^{\circ} \mathrm{C}$, the wind speed never exceeded $3 \mathrm{~m} \mathrm{~s}^{-1}$. Such gradients can only exist where there is little or no mixing induced by the wind. The extreme gradients occur at noon and close to 1600 LST locally. The two peaks are from two deployments in the Gulf of California [see Figs. 4f and 4h in Ward (2006)]. However, it is not clear how representative these data are of a 1D situation, as there is likely some advection occurring during the period of the later extreme gradients. Also, one would need to collect much more individual daily cycles to be able to characterize the shape of the vertical profile in the top meter and its evolution during the daily cycle, preferably simultaneously to the SVP or SVP-BS drifters.

For (ii), one should develop instrumented floats with $C$ and $T$ sensors placed at the same depth and attached to the SVP-BS drifters. This will indicate what the daily cycle $S$ close to the sea surface is; and help better validate the Ttop data and also contribute to a better interpretation of the deeper SVP-BS conductivity data. For example, recent data from a new prototype float attached on a drifter in the equatorial Atlantic suggest (for Pacific Gyre SVP-BS) that the Ttop daily cycle amplitude is slightly less than at $4 \mathrm{~cm}$. These observations are coherent with an equivalent depth of measurement of Ttop deeper than $4 \mathrm{~cm}$.

Acknowledgments. The drifters used in this study and the processing effort were funded by CNES for
TOSCA-supported projects GLOSCAL and SMOS. Simon Morisset was funded by CNES, and the other French authors by CNRS/INSU, IFREMER and MétéoFrance. Some of the drifters used here were also provided by CMM, CNRM, and the Technocean SVP drifters by Louis Marié from LPO, IFREMER. Some of the data were collected during the Gogasmos 2009 cruise on the R/V Antea of IRD, and the 2006 data were collected from drifters deployed during the Pech cruise on R/V Cotes de la Manche of INSU. We are also very indebted to the numerous colleagues for their helping in deploying the drifters during their cruises on French research vessels or from ships of opportunity. Thanks are due to Hana Kanehisa for Fig. 2. B. Ward was supported by an FP7 Marie Curie Reintegration Grant (IRG 224776).

\section{APPENDIX}

\section{Very Large Near-Surface Warming in Drifter Data}

In section 4 (Figs. 9 and 10), we discussed the average shape of the temperature profiles during large daily warming in the top $62 \mathrm{~cm}$. At first order this suggested a rather linear gradient between 15-20 and $62 \mathrm{~cm}$, in particular for daily cycles of $1^{\circ}-3^{\circ} \mathrm{C}$ (possibly even with smaller gradients in the upper part). However, we find a large dispersion in these average results. The most extreme case is for the largest daily warming $\left(4.5^{\circ} \mathrm{C}\right.$ for Ttop) observed for a MetOcean drifter in the Bay of Biscay. In this instance, there was little warming at $62 \mathrm{~cm}$, until the afternoon (1500 LST, Fig. A1). This is not surprising, as such a large daily cycle implies virtually no wind, and thus heat buildup form shortwave absorption strongly confined near the surface with much less warming penetrating deeper. Salinity deduced from conductivity and Tsal does not vary too much until 1500 LST, suggesting also little temperature gradient near $62 \mathrm{~cm}$. There is then a 0.2-psu spike for $2 \mathrm{~h}$ (not shown), either as the result of surface higher salinity water in the cell because of vertical mixing or because the temperature in the conductivity cell (TC) is larger than Tsal. Assuming that this is a real salinity signal and that it extends to the surface would imply 4-mm evaporation during the preceding $6 \mathrm{~h}$. With the very weak wind expected, this exceeds the actual evaporation by at least a factor of 4 . If this were just a temperature effect, would imply a very large TC - Tsal difference, on the order of $1^{\circ} \mathrm{C}$ in $10 \mathrm{~cm}$. We cannot quantify this further, as the Tsal measurement is made near the middle of the cell on this MetOcean drifter, and we do not know what sets the temperature in the cell. Both effects, however, clearly indicate that some mixing with the surface water 

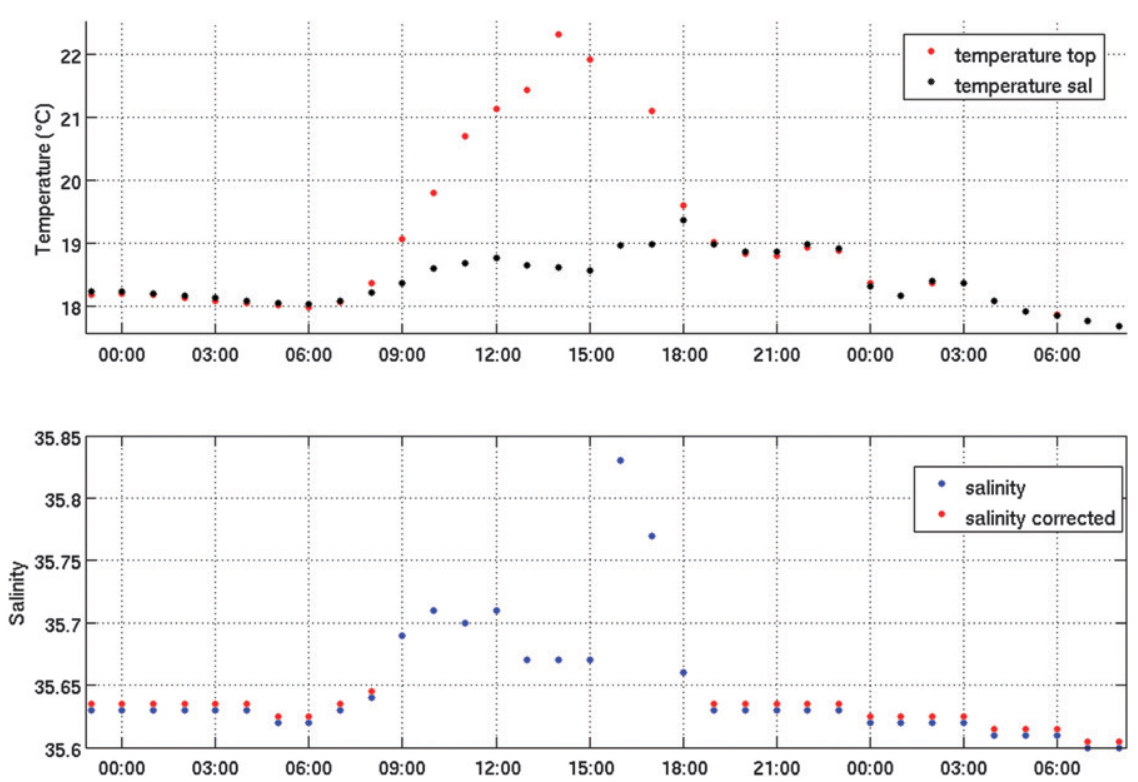

FIG. A1. Daily cycle of extremes in the Bay of Biscay on 18 Jun 2009 (MetOcean drifter 300034012164270): (top) Ttop and Tsal; (bottom) $S$ and $S$ corrected using $C$ and Tsal.

penetrates to the cell's depth in a still stratified layer around 1500 LST, until mixing fully homogenizes this upper layer after 1700 LST. This is thus indicative of a succession of contributions to the daily warming at $62 \mathrm{~cm}$. First, the slow warming until 1500 LST probably results from direct radiative flux convergence, whereas after 1500 LST, the penetration of vertical mixing to the sensor depth in the stratified layer induces the late afternoon warming observed at 62-cm depth in Fig. A1. In this extreme example, the temperature profile clearly deviated from a nearly linear gradient before 1500 LST.

We also had earlier multisensor drifters in 2006 in the same region-season in the Bay of Biscay (near $43^{\circ}-44^{\circ} \mathrm{N}$ ), which presented daily warming (Ttop) larger than $2^{\circ} \mathrm{C}$ in four instances (including two $>3^{\circ} \mathrm{C}$ ). We can construct profiles using a combination of sensors at the
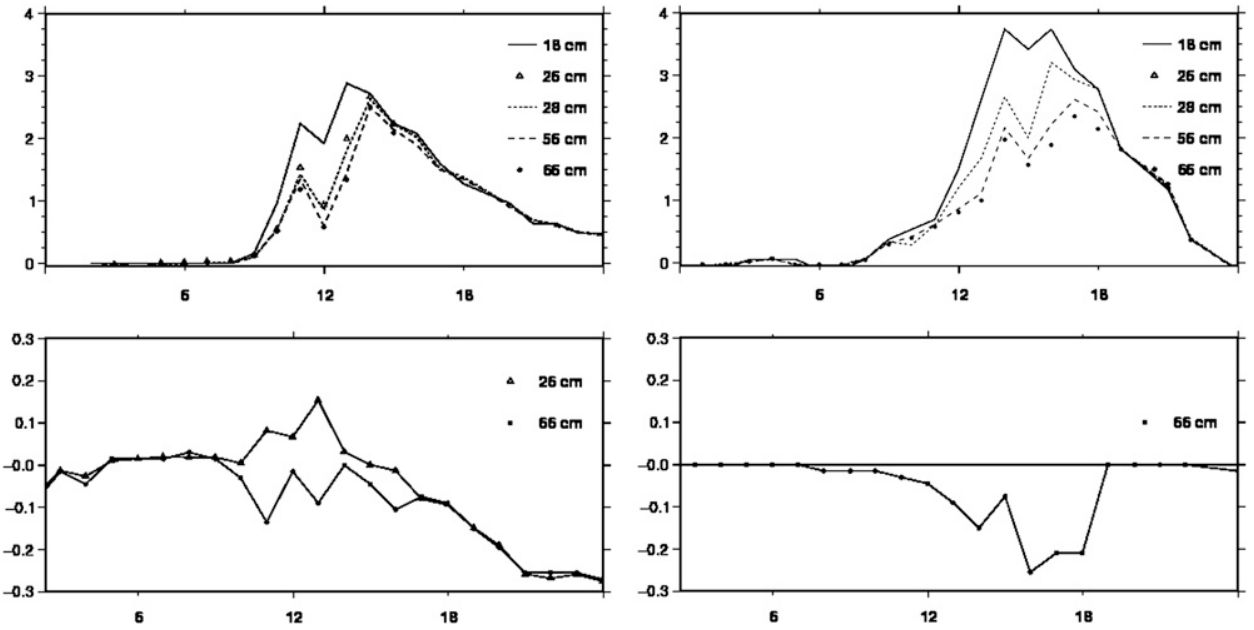

FIG. A2. (left) Large daily cycle (7 July 2005) of (top) $T$ and (bottom) $S$ in the southern Bay of Biscay from MetOcean SVP-BS drifter 52187 with additional sensors from an attached instrumented buoy. Local standard time is on horizontal axis, and the amplitude of the warming and the increase in $S$ since the morning minimum $\left({ }^{\circ} \mathrm{C}\right.$ and psu, respectively) are on the vertical axis. Plotted symbols are estimates of TC from conductivity measurements with the curves corresponding to the different temperature measurements. (right) As in (left), but for 18 July 2006. 
depths: Ttop near 18, 28, 56, and $66 \mathrm{~cm}$ (sometimes also at $26 \mathrm{~cm}$ ). The profiles do not match the example in Fig. A1, but there are some common features. The two instances with the largest daily warming (Fig. A2) also indicated a strong vertical stratification intensified by at least a factor of 2 above $28 \mathrm{~cm}$ than below in the morning-early afternoon (for the 7 July daily cycles, the data at $26 \mathrm{~cm}$ are also available that confirm the gradient between 18 (Ttop) and $28 \mathrm{~cm}$, and thus the validity of Ttop). In the early (or mid) afternoon, vertical mixing slowly started to diminish the near-surface gradient, resulting in a more linear profile down to $66 \mathrm{~cm}$. Eventually (in $<3 \mathrm{~h}$ ), the layer got completely mixed. Thus, it results in later temperature peaks at $66 \mathrm{~cm}$ than near $18 \mathrm{~cm}$, as was found in Fig. 7 for the smaller daily cycle and in Fig. A1 for this extreme daily cycle.

Autonomous profiler data [Skindeep or Air-Sea Interaction Profiler (ASIP); Ward and Fristedt 2008] also show the strongest temperature stratification remaining close to the sea surface through the early afternoon of some days with little wind, and certainly not extending down to $66 \mathrm{~cm}$. This is also conceptually reproduced by models such as POSH (Gentemann et al. 2009), which retain the stronger near-surface stratification as long as there is no wind and some surface heating. Interestingly, we witness less this larger near-surface stratification in the summary of drifter data provided in Figs. 9 and 10, but which for the large daily cycles $\left(>2.5^{\circ} \mathrm{C}\right)$ correspond mostly also to tropical deployments with very high sun elevation.

\section{REFERENCES}

Bellenger, H., and J.-P. Duvel, 2009: An analysis of tropical ocean diurnal warm layers. J. Climate, 22, 3629-3646.

_ , Y. N. Takayabu, T. Ushiyama, and K. Yoneyama, 2010: Role of diurnal warm layers in the diurnal cycle of convection over the tropical Indian Ocean during MISMO. Mon. Wea. Rev., 138, 2426-2433.

Bernie, D. S., S. J. Woolnough, J. M. Slingo, and E. Guilyardi, 2005: Modeling diurnal and intraseasonal variability of the ocean mixed layer. J. Climate, 18, 1190-1202.

Brunke, M. A., X. Zeng, V. Misra, and A. Beljaars, 2008: Integration of a prognostic sea surface skin temperature scheme into weather and climate models. J. Geophys. Res., 113, D21117, doi:10.1029/2008JD010607.

Castro, S. L., G. A. Wick, and W. J. Emery, 2012: Evaluation of the relative performance of sea surface temperature measurements from different types of drifting and moored buoys using satellite-derived reference products. J. Geophys. Res., 117, C02029, doi:10.1029/2011JC007472.

Emery, W. J., D. J. Baldwin, P. Schlüssel, and R. W. Reynolds, 2001: Accuracy of in situ surface temperatures used to calibrate infrared satellite measurements. J. Geophys. Res., 106, 2387-2405, doi:10.1029/2000JC000246.

Fairall, C. W., E. F. Bradley, D. P. Rogers, J. B. Edson, and G. S. Young, 1996: Bulk parameterization of air-sea fluxes for
Tropical Ocean-Global Atmosphere Coupled-Ocean Atmosphere Response Experiment. J. Geophys. Res., 101 (C2), 3747-3764.

Filipiak, M. J., C. J. Merchant, H. Kettle, and P. Le Borgne, 2012: An empirical model for the statistics of sea surface diurnal warming. Ocean Sci., 8, 197-209, doi:10.5194/ os-8-197-2012.

Gentemann, C. L., P. J. Minnett, P. Le Borgne, and C. J. Merchant, 2008: Multi-satellite measurements of large diurnal warming events. Geophys. Res. Lett., 35, L22602, doi:10.1029/ 2008GL035730.

- _ — , and B. Ward, 2009: Profiles of ocean surface heating (POSH): A new model of upper ocean diurnal warming. J. Geophys. Res., 114, C07017, doi:10.1029/2008JC004825.

Johnson, R. H., T. M. Rickenback, S. A. Rutledge, P. E. Ciesielski, and W. H. Schubert, 1999: Trimodal characteristics of tropical convection. J. Climate, 12, 2397-2418.

Kawai, Y., and H. Kawamura, 2000: Study on a platform effect in the in situ sea surface temperature observations under weak wind and clear sky conditions using numerical models. J. Atmos. Oceanic Technol., 17, 185-196.

— , and — 2002: Evaluation of the diurnal warming of sea surface temperature using satellite derived marine meteorological data. J. Oceanogr., 58, 805-814.

— tion and its impact on the atmosphere and ocean: A review. J. Oceanogr., 63, 721-744.

—, K. Ando, and H. Kawamura, 2009: Distortion of near-surface seawater temperature structure by a moored-buoy hull and its effect on skin temperature and heat flux estimates. Sensors, 9 , 6119-6130, doi:10.3390/s90806119.

Kennedy, J. J., P. Brohan, and S. F. B. Tett, 2007: A global climatology of the diurnal variations in sea-surface temperature and implications for MSU temperature trends. Geophys. Res. Lett., 34, L05712, doi:10.1029/2006GL028920.

Le Borgne, P., G. Legendre, and S. Péré, 2012: Comparison of MSG/SEVIRI and drifting buoy derived diurnal warming estimates. Remote Sens. Environ., 124, 622-626, doi:10.1016/ j.rse.2012.06.015.

Marullo, S., R. Santoleri, V. Banzon, R. H. Evans, and M. Guarracino, 2010: A diurnal-cycle resolving sea surface temperature product for the tropical Atlantic. J. Geophys. Res., 115, C05011, doi:10.1029/2009JC005466.

McGillis, W. R., W. E. Asher, R. Wanninkhof, A. T. Jessup, and R. A. Feely, 2004: Introduction to special section: Air-sea exchange. J. Geophys. Res., 109, C08S01, doi:10.1029/ 2004JC002605.

Merchant, C. J., M. J. Filipiak, P. Le Borgne, H. Roquet, E. Autret, J.-F. Piollé, and S. Lavender, 2008: Diurnal warm-layer events in the western Mediterranean and European shelf seas. Geophys. Res. Lett., 35, L04601, doi:10.1029/ 2007GL033071.

O'Carroll, A. G., J. R. Eyre, and R. W. Saunders, 2008: Three-way error analysis between AATSR, AMSR-E, and in situ sea surface temperature observations. J. Atmos. Oceanic Technol., 25, 1197-1207.

Parsons, D. H., M. A. Shapiro, and E. Miller, 2000: The mesoscale structure of a nocturnal dryline and a frontal dayline merger. Mon. Wea. Rev., 128, 3824-3838.

Reverdin, G., P. Blouch, J. Boutin, P. Niiler, J. Rolland, W. Scuba, A. Lourenço, and A. Rios, 2007: Surface salinity measurementsCOSMOS 2005 experiment in the Bay of Biscay. J. Atmos. Oceanic Technol., 24, 1643-1654. 
- , and Coauthors, 2010: Drifters surface temperature measurements. J. Atmos. Oceanic Technol., 27, 1403-1409.

Shinoda, T., 2005: Impact of the diurnal cycle of solar radiation on intraseasonal SST variability in the western equatorial Pacific. J. Climate, 18, 2628-2636.

Stuart-Menteth, A. C., I. S. Robinson, and P. G. Challenor, 2003: A global study of diurnal warming using satellite-derived sea surface temperature. J. Geophys. Res., 108, 3155, doi:10.1029/ 2002JC001534.

Ward, B., 2006: Near-surface ocean temperature. J. Geophys. Res., 111, C02005, doi:10.1029/2004JC002689.

_ _ and T. Fristedt, 2008: Air-sea interaction profiler: Autonomous upper ocean measurements. Proc. 2008 IEEE/OES US/ EU-Baltic Int. Symp., Talinn, Estonia, IEEE, 1-8, doi:10.1109/ BALTIC.2008.4625494.
R. Wanninkhof, W. R. McGillis, A. T. Jessup, M. D. DeGrandpre, J. E. Hare, and J. B. Edson, 2004a: Biases in the air-sea flux of $\mathrm{CO}_{2}$ resulting from ocean surface temperature gradients. J. Geophys. Res., 109, C08S08, doi:10.1029/ 2003JC001800.

$\longrightarrow,-$, P. J. Minnett, and M. J. Head, 2004b: SkinDeEP: A profiling instrument for upper-decameter sea surface measurements. J. Atmos. Oceanic Technol., 21, 207-222.

Woolnough, S. F. J., F. Vitard, and M. A. Balmaseda, 2007: The role of the ocean in the Madden-Julian Oscillation: Implications for MJO prediction. Quart. J. Roy. Meteor. Soc., 133, $117-128$

Yokoyama, R., S. Tanba, and T. Souma, 1995: Sea surface effects on the sea surface temperature estimation by remote sensing. J. Remote Sens., 16, 227-238. 